\title{
New Modes of Instructions for Electrical Engineering Course Offered to Non- Electrical Engineering Majors
}

\section{Seemein Shayesteh P.E., Indiana University Purdue University, Indianapolis}

Lecturer in the department of Electrical and Computer Engineering at Purdue School of Engineering at Indianapolis

\section{Dr. Maher E. Rizkalla, Indiana University Purdue University, Indianapolis}

Dr. Maher E. Rizkalla: received his PhD from Case Western Reserve University in January 1985 in electrical engineering. From January 1985 until August 1986 was a research scientist at Argonne National Laboratory, Argonne, IL while he was a Visiting Assistant Professor at Purdue University Calumet. In August 1986 he joined the department of electrical and computer engineering at IUPUI where he is now professor and Associate Chair of the department. His research interests include solid state devices, applied superconducting, electromagnetics, VLSI design, and engineering education. He published more than 175 papers in these areas. He received plenty of grants and contracts from Government and industry. He is a senior member of IEEE and Professional Engineer registered in the State of Indiana 


\section{New Modes of Instructions for Electrical Engineering Course Offered to Non-Electrical Engineering Majors}

\section{Introduction}

The traditional electrical circuits course within the mechanical engineering (ME) curriculum was designed to familiarize the ME students with linear circuits, including DC and $\mathrm{AC}$ analyses. The course was serving a narrow scope that included hands-on practice in linear circuits and on using instrumentations and equipment. The ME students were taking the introductory electrical and computer engineering course with electrical and computer engineering (ECE) students. Close scrutiny to the ME students' satisfaction and future benefits of the course suggested that a new course must be developed for the ME curriculum that serves a more comprehensive scope for the following purposes:

1. Expose the ME students to digital and analog electronics, with hands-on practice; exposure should assist the ME students with their senior design projects in the senior year for projects that require computer interfacing and digital control systems.

2. Assist ME students with multi-disciplinary research that the ME students may take advantage of when using digital and analog electronics. Recent energy conversion processes that are often covered throughout the ME curriculum may require background from analog and digital electronics.

3. Offer the ME students with the opportunity to pursue a signal-processing track within the ECE Curriculum that is important for industry applications when participating in multidisciplinary projects.

The feedback from the departmental industrial board also recommended the development of this new course for the ME curriculum that satisfies the above goals.

In our institute, a team of ECE faculty members has participated in the development of a new lecture/lab course that better prepares the ME students for hands on digital control and signal processing interdisciplinary projects. The new course has been developed and offered for more than 6 years. Routine assessment data indicated the importance of revising the course in order to incorporate new modes of instructions to link the course materials into the ME mainstream. With this update, the students can see the immediate use of the materials within the ME curricula. Some schools across the country have followed similar approaches ${ }^{1-6}$ in updating the ME course and making it appropriate for future applications; however, the approach followed here is unique since it applies $\mathrm{ME} / \mathrm{ECE}$ engineering analogies and applications that crosses the gaps between the two disciplines.

This paper provides the details of the new ME "electrical and electronics circuits" course that covers a combination of linear circuits, and analog and digital electronics, associated with a laboratory component. The paper also addresses the new modes of instructions that made the course more advanced and appropriate for the ME curricula. ECE/ME analogies were incorporated at various sections of the course. The paper also details the important 
elements and applications used in the ME/ECE analogies. Also, the role of mechanical engineering in electrical system design was emphasized. Thermal analyses and physical packaging methods in electronics' designs for various applications are strongly linked to many of the ME disciplines. Examples of those analogies are emphasized.

\section{Course Structure and Approaches}

The ME new course was structured to cover linear circuits and devices, and digital electronics. The amount of the material may seem to be too much for one semester course; however, the approach used in the course covers methodologies with computer simulation approach to reduce the time scheduled for some linear circuit sections. The dependent voltage and current sources, for instances, were minimized in the course to enable more digital circuits coverage, and were referenced only as needed, e.g. in device simulation. The analog components using MOSFET and BJT devices were handled with equivalent circuits as part of the circuit analyses of the course. Table 1 shows the structure of the course. The lecture covers linear circuits, analog electronics, and digital electronics. For each lecture subject, there is a laboratory component that is conducted simultaneously with the lecture material. In addition, to better satisfy the course objectives, team projects with applications and examples to illustrate role of mechanical engineers in electrical system design, were covered in the second half of the course.

\section{II.1 Mechanical / Electrical System Analogy}

Students are given an introduction to the importance of using electrical and electronics components in mechanical systems, and the use of digital control, and computer signal processing. The new addition of the course incorporated ME/ECE analogies that emphasize elements from thermodynamics, fluid mechanics, energy, and applications. Analogies between current and flow, and voltage and pressure, are common in thermodynamics and fluid mechanics, where mechanical parameters can be modeled by electrical parameters. KCL for instance represents conservation of charges at any node, which is analogous to the flow of fluids in and out of any node and conservation in fluid mechanics. Boiler system for instance is a good example that presents the relation between temperature, volume, and pressure, which can be modeled as capacitors, resistors, and electrical elements. The applications of electronics in packaging integrate much of thermal sciences with electronics. The electrical power and thermal energy are always related to the conservation of energy, which is the first law of thermodynamics. Behaviors of chemical battery systems such as charging and discharging, heating issues, etc., can be also modeled with circuit parameters, and can be part of this section of the course.

\section{II.2 Engineering Applications}

In this update, students are required to find engineering applications, where electrical circuit parameters can model mechanical parameters. Students are guided in their search via applications of thermodynamics within a battery system. Exercises using mechanical sensors for flow, temperatures, pressures, etc., can be converted into analogous electrical parameters such as resistances, and capacitances. Also, the employment of transistors in 
signal processing in sensors is an exciting area for ME students when applied to automotive and energy conversion. Such topics prepare ME students for future MEMS (microelectromechanical systems) research.

Table 1: Course Structure

\begin{tabular}{|c|c|c|}
\hline & Lecture & Lab \\
\hline \multirow{6}{*}{ 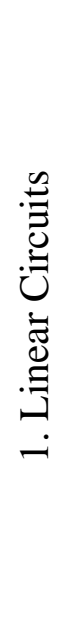 } & $\begin{array}{l}\text { Definition, KVL, KCL, Series \& Parallel } \\
\text { Resistances, Ohm’s Law, Power }\end{array}$ & $\begin{array}{l}\text { Introduction to breadboard and } \\
\text { measurements }\end{array}$ \\
\hline & $\begin{array}{l}\text { Voltage and Current Sources, Measuring } \\
\text { Devices }\end{array}$ & Voltage and Current Divider Circuits \\
\hline & $\begin{array}{l}\text { Node Voltage, Mesh Curent, } \\
\text { Superposition }\end{array}$ & $\begin{array}{l}\text { Node Voltage and Mesh Current } \\
\text { Analysis }\end{array}$ \\
\hline & Thevenin and Norton Equivalent Circuits & $\begin{array}{l}\text { Thevenin Equivalent Circuit and } \\
\text { Maximum Power Transfer }\end{array}$ \\
\hline & Time Dependent Signal Sources & Oscilloscope and Function Generator \\
\hline & AC Signal / Phasor Analysis & $\begin{array}{l}\text { Phase Measurements for RL and RC } \\
\text { Circuits }\end{array}$ \\
\hline \multirow{4}{*}{ 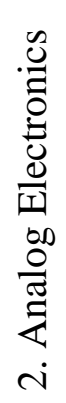 } & $\begin{array}{l}\text { First Order Differential Equations L \& C, } \\
\text { Transient Analysis }\end{array}$ & $\begin{array}{l}\text { Transient Analysis in RL and RC } \\
\text { Circuits }\end{array}$ \\
\hline & Operational Amplifiers and Diodes & Operational Amplifiers \\
\hline & Bipolar Junction Transistors & Bipolar Junction Transistors \\
\hline & MOSFETs & MOSFETs \\
\hline \multirow{4}{*}{ 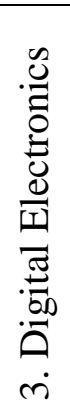 } & $\begin{array}{l}\text { Binary Number System, Boolean Algebra, } \\
\text { Logic Gates }\end{array}$ & Basic Logic gates \\
\hline & Combinational Logic Modules & Combinational Logic \\
\hline & Combinational Logic Modules & BCD to 7 Segment Display Example \\
\hline & Sequential Logic Modules & Sequential Circuits \\
\hline \multirow{3}{*}{ 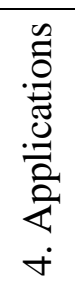 } & \multicolumn{2}{|c|}{ Analogous Systems } \\
\hline & \multicolumn{2}{|c|}{ Applications } \\
\hline & \multicolumn{2}{|c|}{ Role of mechanical engineers in electrical system design } \\
\hline
\end{tabular}




\section{II.3 Role of Mechanical Engineers in Electrical System Design}

Proliferation of enhanced-feature integrated electrical systems -- from sub-micron integrated circuit technology to high frequency Wi-Fi wireless applications -- continues even as global market competition demands systems with lower cost, lighter weight and smaller size. Increasingly the role of mechanical engineers in multidisciplinary teams in the workplace is highly critical in the success of systems' design and performance. The traditionally mechanical disciplines such as manufacturing, packaging, board layout, wire bonding, heat transfer, etc. have a profound impact on an electrical design. It is critical that non-EE team members know basic electronics concepts. To boost students' interest, this message is conveyed to students in this required analog / digital course. Below are three examples presented in the class of fall 2015 throughout the second half of the course to emphasize a mechanical engineer's role in a multidisciplinary projects:

1. An electrical low-pass filter was designed and simulated to "pass" the Bluetooth RF band (2.4- $2.5 \mathrm{GHz})$ to an antenna. After the board design was built, the $2.4 \mathrm{GHZ}$ signal at the antenna was observed to be at $10-20 \mathrm{~dB}$ lower level than expected, and the wireless range of the Bluetooth device was greatly degraded. The assembly factory confirmed that all the L/C components were of the correct values. After extensive investigation, a circuit-board lay-out problem was discovered. One of the two shunt capacitors was seen to be laid-out with a long copper trace. The discrete surface-mount capacitor had a size of $0.5 \mathrm{~mm} \times 1.0 \mathrm{~mm}$, but the copper trace used on the circuit-board was nearly $5 \mathrm{~mm}$ long. The long copper trace had caused an undesired "notch" response near $2.4 \mathrm{GHz}$ due to resonance of the discrete capacitor with the inductance of the copper trace.

2. Two microprocessors on a printed-circuit board initially generated too much heat. Each microprocessor BGA (Ball Grid Array) has 25X25=625 solder-balls for its high-speed electrical connections. Microprocessor clocks runs at $800 \mathrm{MHz}$ or greater, with every clocked event generating finite thermal power dissipation. The initial plastic-IC-package with no "heat-fins" on top, although cost effective, did not provide enough heat escapes and a new packaging scheme was needed. Extensive use of simulations, finite-element analysis and comparisons of several possible solutions (material costs, tooling costs, etc.) led to the final packaging scheme that used a metal enclosure in which the cover-piece had tool-formed depressions. Depressions (along with high-conductivity interface materials) provided heatsinking to the microprocessors. Figure 1 showe the initial and final nackaging.
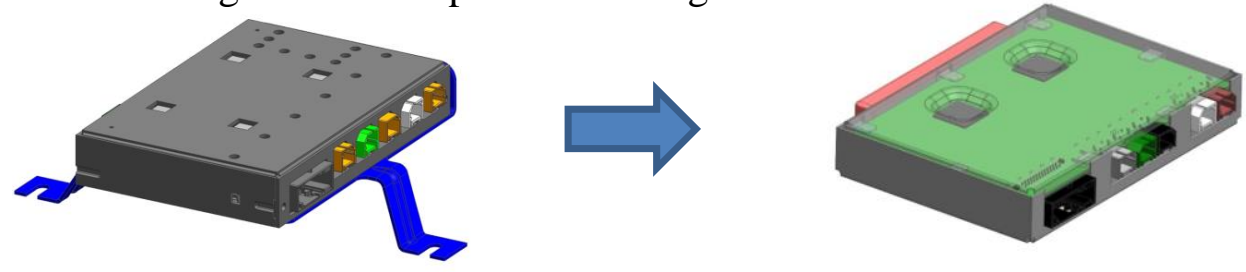

Figure 1: Packaging scheme modifications to reduce heat 
3. A circuit-board platform that was in production for several months and had worked well was found to be very sensitive to EMC problems. The Bluetooth RF performance was degraded and no one knew the reason. For example, Bluetooth wireless link range was greater than 20 meters at initial production and was reduced to less than 1 meter at later production. It turned out that a digital-IC supplier had implemented a "die shrink" 11 at the silicon level and had kept the IC package the same. The die shrink in itself would probably have worked OK. However, longer bond-wires had to be used to implement the smaller silicon-die in the existing ICpackage and PC board. Bond-wires and board traces acted as radiating elements for fast-transition electrical events and had caused EMC problems at RF frequencies in the Bluetooth band. To eliminate the problem, the IC-supplier ended up shipping the older "large die" parts for lifetime of the board design.

\section{Analogy Project Examples in Recent Course Offerings}

Typically there are 8-10 group presentations every semester, reporting their research efforts for electrical-mechanical, electrical-thermal and electrical-hydraulic analogies. For fall 2015, there were 9 groups, of 4 students each. The following are typical examples of what students presented in the analogies between the different systems ${ }^{7-10}$.

\section{Example 1: Mechanical Pump Modeling}

As a pump takes in water at low pressure, does mechanical work on it, and ejects it at high pressure, a battery takes in charge at low voltage and does electrochemical work on it to eject high voltage. Voltage is analogous to pressure and current is analogous to volume flow rate. Analogous systems are shown in Figure 2.

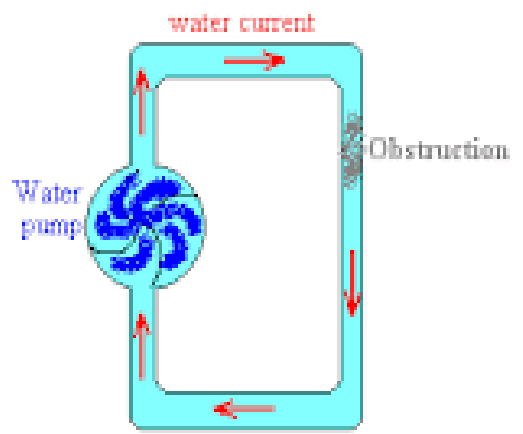

Water Curcut

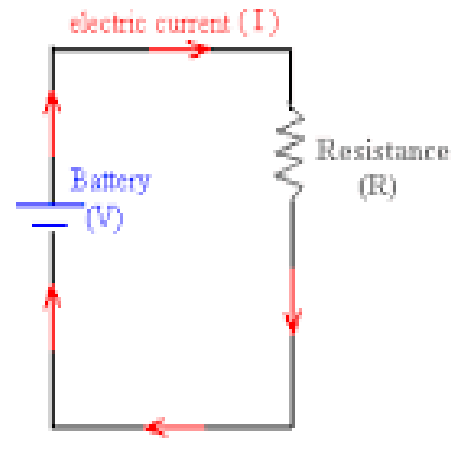

Electrical Circuit

Figure 2: Mechanical Pump Modeling

\section{Example 2: Electrical Circuit / Thermal System Analogy}

Kirchhoff's voltage law relates to conservation of energy in a closed system. For example, a stove-top heats up and returns to its initial temperature. In a related thermal analogy example, a group of students compared an electrical capacitance to a heat storage element. A thermos mug is known to keep heat in for long periods of time due to minimized conduction and radiation flows. 


\section{Example 3: Forms of Energy Conversion}

Energy stored in springs and masses by potential energy and kinetic energy is related to energy stored in capacitors and inductors by electric and magnetic fields. As a damper dissipates energy into heat, so does a resistor. Figure 3 illustrates the analogy.

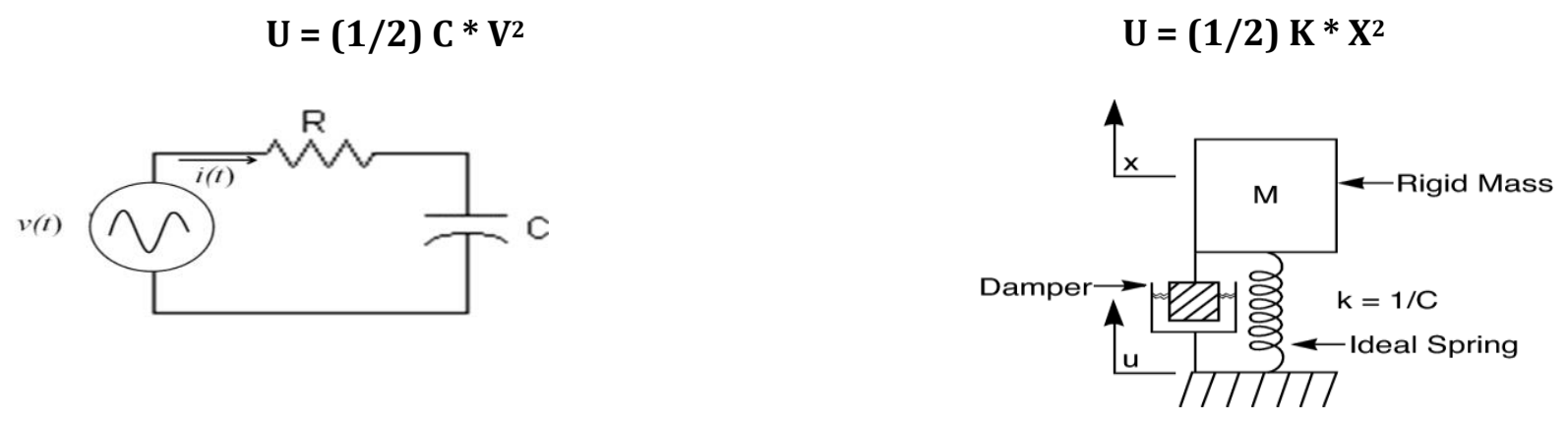

Figure 3: Forms of energy conversion

\section{Example 4: Electrical / Hydraulic System}

The students were able to describe the flow from a low-pressure liquid reservoir to a pump where high pressure is generated, and then fed back to the reservoir. The mechanical sources and parameters represented by the pump, flowrate, mechanical torque, angular velocity, angle, power, energy, narrowing in pipes, etc., can be analyzed with analogous electrical methods. Analogous electrical sources and parameters for this mechanical system include current, voltage, charge, electrical torque, electrical power and energy, resistances, capacitances, KVL / KCL, and inductors. The mechanical / hydraulic system has also transient performance. Likewise, the analogous electrical system with RLC second order electrical circuit exhibits transient behavior. Figure 4 reflects the analogies of the various components.

The transient performance and steady state perfomance of the first order circuits is covered as part of the course. The transient behavior of the electrical circuit could be translated into the mechanical parameters. In figure $4 \mathrm{c}$ below, the spring is analogous to the capacitor, and the mechanical damper to the resistor.

The analogous system brings attached learning from the ME knowledge that is frequently covered at the ME curriculum. The positive impacts of these examples have stimulated exciting discussions among ME students. 


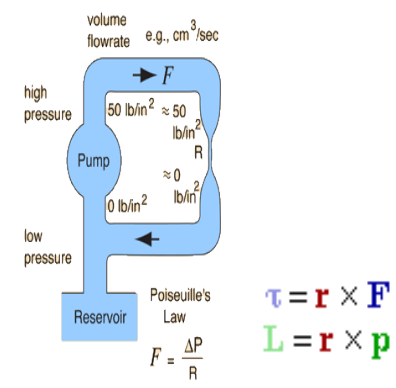

(a)

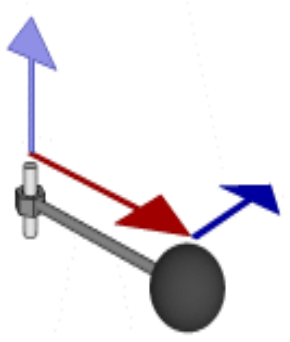

(b)

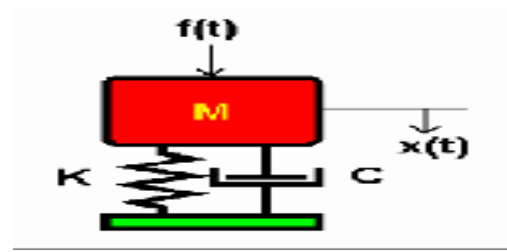

(c)

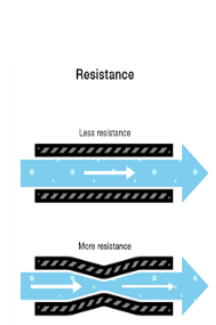

(d)

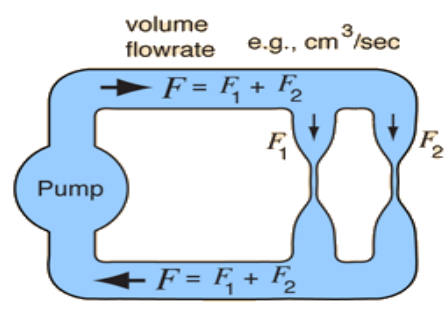

(e)

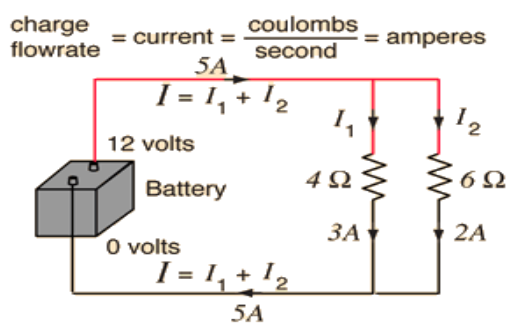

(f)

Figure 4. Electrical / Hydraulic Analogy Example: (a) Hydraulic Mechaical System, (b) Mechanical parameters; Torque/Angular velocity/Angle analogy, (c) concept of resistance and capacitance, (d) Mechanical Flow and restriction in flow, (e) Hydraulic system with flow branching, and (f) analogous electrical system with current node.

\section{Results and Discussion}

An issue of "too abstract and not too visible" ECE content materials was often cited by non-electrical engineering majors when pursuing an electrical engineering course. To alleviate the perception, this course was designed to be project portfolio based course with simulation and modeling attached to the course. The pedagogical methodology was developed to enable the instructor to provide new experiences for the ME students that integrate many of the ME elements throughout the ME curriculum. The framework of the course incorporates attached projects, applications, group discussions, and group presentation. In contrast to the traditional courses that use only a textbook approach, this course delivers new modes of instructions that provide students with project experience and attached applications. Coverage of the extensive amount of course materials was assisted by the software simulation and modeling distributed throughout the course. The new approach promotes interaction between students and the instructor, and collaboration and cohesion between the team members. The course also elaborates on the mathematical procedures, schematics, and the software tools to give students the ability to approach problem solving with reasoning and to interpret simulation and practical data. 


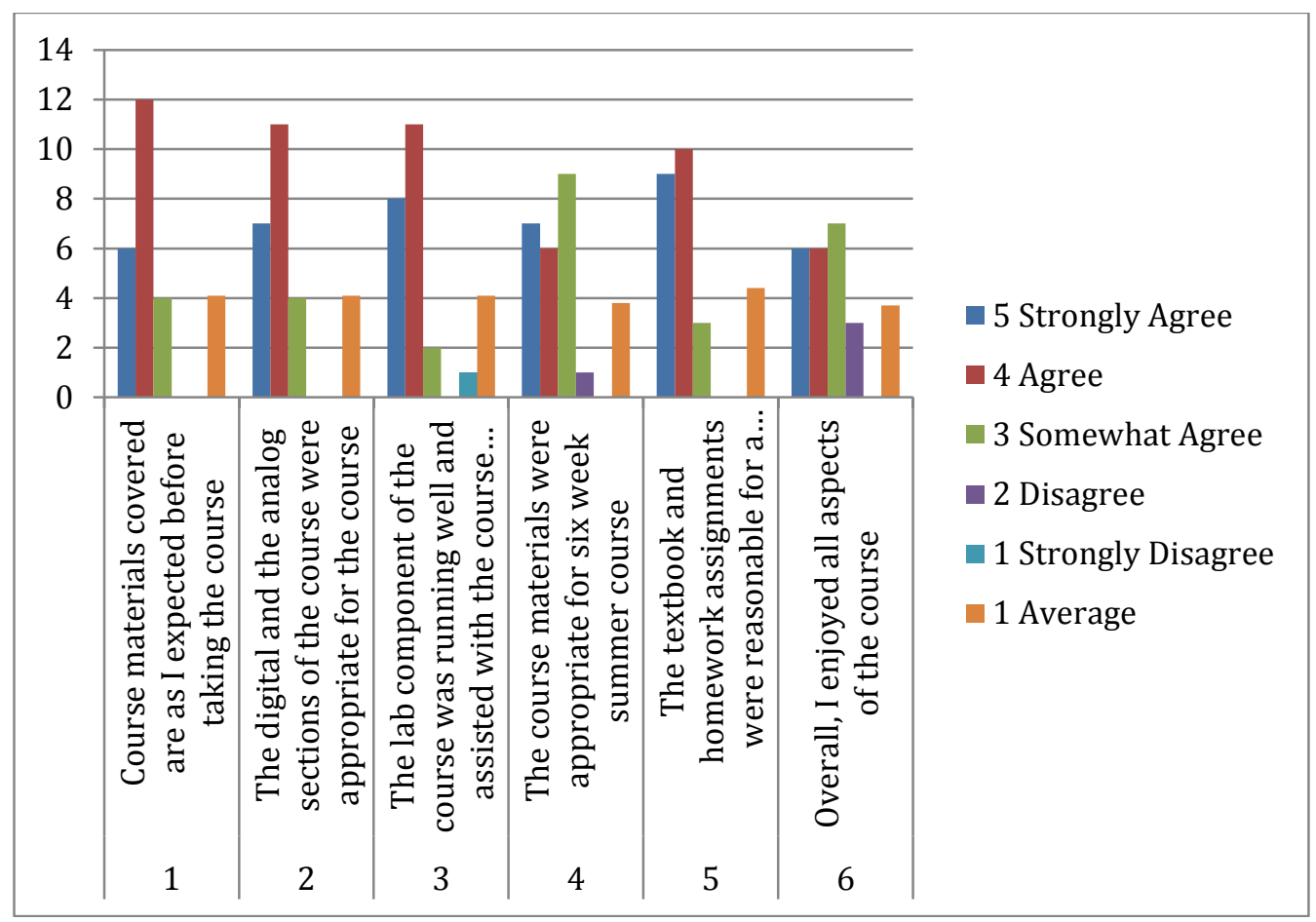

Figure 5: Summer 2015 Survey Results

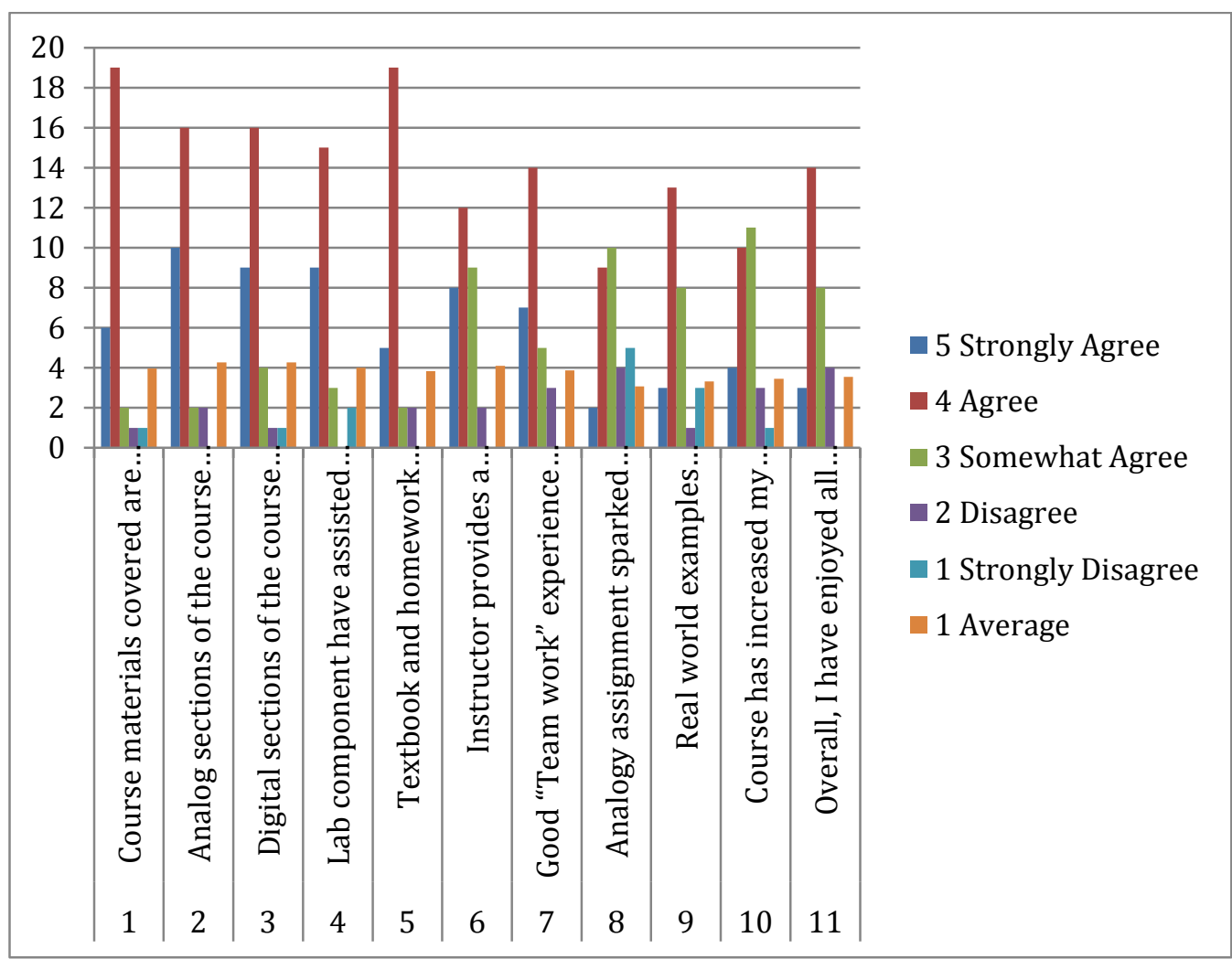

Figure 6: Fall 2015 Survey Results 
The course considers pre-requisite materials that include a 5 credit hour physics course (Phys 251 - Heat, Electricity and Optics), where electrical foundations are established to pursue this course.

Figure 5 and Figure 6 show excerpts of the students' course satisfaction survey results from summer 2015 and fall 2015 respectively.

As it appears from both sets of data, students have enjoyed all aspects of the course with an average above 3.8 out of 5 .

At the end of each semester a course outcome survey is also conducted where students rate how well they can perform each of the course outcomes (competency learning objectives). The average course outcome survey results from spring 2013 through spring 2015 have been consistently high and above 3.6 out of 5 as shown in Figure 7.

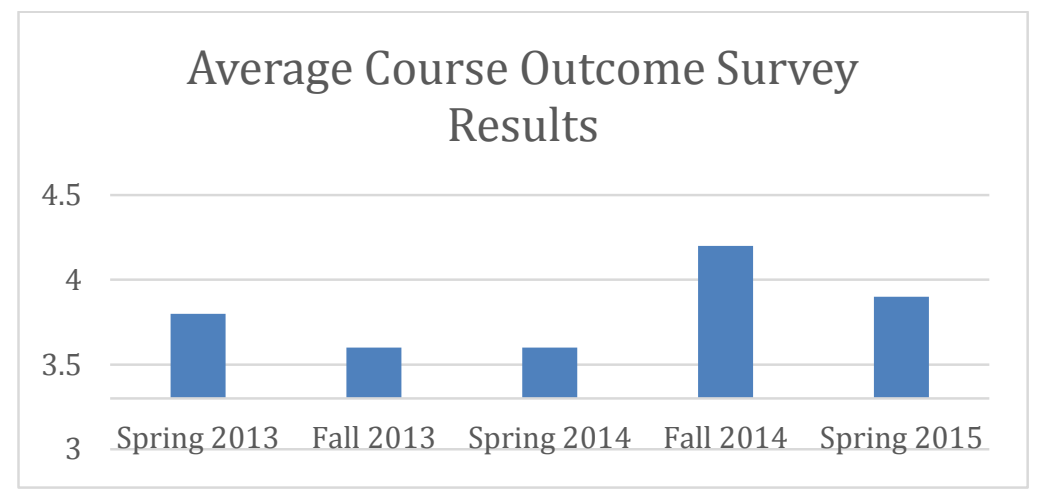

Figure 7: Average Course Outcome Survey Results

In addition, the course-specific GPAs in summer 2015 and fall 2015 were above 2.8 out of 4.0. This is much higher than the typical overall GPA in the required electrical engineering courses for the Electrical and Computer Engineering majors.

The new course structure has given some students more knowledge on what is covered in electronics to enable them to pursue further education in joint projects. Most importantly, the course has given the ME students the electronics foundation to use electronics control with hardware that could be necessary for the completion of the final products. Specifically, the revised electrical and electronics engineering course for non-electrical engineering majors has provided background for the ME students in their senior design projects. Simulation of the mechanical systems via electrical parameters is of great use. Several examples may include storage devices such as battery systems, fuel cells, and ultra-capacitors. Projects related to thermal sciences may also need thermal sensors and signal processing. The area of digital control and robotics inquire background from electrical and electronics circuits. Furthermore, the multidisciplinary undergraduate research initiative program (MURI) encompasses ideas from digital control and mixed signals. ME students also wish to have career-relevant project topics, and fast-growing new ME career areas such as Renewable Energy are increasingly dependent on electronics 
for power switching, analog processing for mechatronics, circuit modeling and MEMS (microelectromechanical systems).

Specific examples of recent mechanical engineering senior design projects include:

1. Thermal Solution for Smart Display

2. E-Lock for Vertical Exit Device

3. Home HVAC control system development

4. Child Therapy Ride-On Electric Vehicle

5. Power Distribution Component Optimization

6. Robotic Football Player

7. High Torque Density Electric Motor

8. Power Line Automated Maintenance Device

Project choices such as above are screened via an instructor committee to insure proper course background that enables students to pursue the projects. The revised course is essential to the students for the development of these projects.

\section{Conclusion}

Peer-led teams have presented effective analogies to observe the connection of electrical engineering concepts and mechanical engineering equivalent systems. These, in addition to circuit simulation and hands-on laboratory experiments, have encouraged creative thinking, teamwork and active class participation.

The students' satisfaction with the course materials, have resulted in their preparation to pursue research in multidisciplinary research. The new course may serve as a model for the ME program offered elsewhere to prepare students towards multidisciplinary career. 


\section{References}

1. http://multimechatronics.com/images/uploads/mech_n/Electrical_Mechanical_Analogy.pdf

2. Kumar Yelamarthi, Sridhar Ramachandran, P. Ruby Mawasha, "The Practical use of Analogies to Mentor the Engineer of 2020", American Society of Engineering Education 2006 Illinois Indiana and North Central Joint Section Conference

3. http://ocw.mit.edu/courses/electrical-engineering-and-computer-science/6-777j-design-and-fabricationof-microelectromechanical-devices-spring-2007/lecture-notes/07lecture08.pdf

4. Alexander Ganago, Sudarshan Sivaramakrishnan, Robert Matthew DeMonbrun, "Development of student motivation in a required Electrical Engineering (EE) course for non-EE majors", $121^{\text {st }}$ ASEE Annual Conference and Exposition

5. Alexander Ganago, Hongwei Liao, "Student learning in a required Electrical Engineering (EE) course for non-EE majors: Perception of values for future work in multidisciplinary teams", $120^{\text {th }}$ ASEE Annual Conference and Exposition, June 23-26, 2013

6. R. William Graff, Paul R. Leiffer, "Demonstration of Electrical Principles in the Classroom by Hydraulic Analogues", 2013 ASEE Annual Conference, June 23-26, 2013

7. https://learn.sparkfun.com/tutorials/voltage-current-resistance-and-ohms-law/all

8. Rizzoni, Giorgio. Fundamentals of Electrical Engineering. Dubuque, IA: McGraw-Hill.

9. http://hyperphysics.phy-astr.gsu.edu/hbase/electric/watcir.html

10. http://lpsa.swarthmore.edu/Analogs/ElectricalMechanicalAnalogs.html\#Mech_2_to_Electrical

11. https://en.wikipedia.org/wiki/Die_shrink 